\title{
Response: Is there a case for risk-based premiums in health care insurance?
}

\author{
ALISTAIR MCGUIRE* \\ The London School of Economics and Political Science, Houghton Street, London WC2A 2AE, UK
}

The paper by Peter Zweifel and Michael Breuer (ZB) offers a stimulating technical discussion of rationales for using risk-based insurance premiums in a social insurance environment where moral hazard is present. The basic argument runs as follows. Moral hazard may be deemed ex ante or ex post; the former is associated with an insured individual influencing the observed probability of illness through not taking optimal preventative measures, while the latter arises from over-consumption of health care at time of illness. Following the statement that, in theory, risk sharing is optimal under such circumstances, the bulk of the paper is concerned with outlining the conditions under which demand-side risk sharing remains optimal given an environment of social insurance. The argument continues by suggesting that, given a budget break-even constraint, uniform premiums are not profitable as high-risk individuals may be an incentive for the insurers to select risks in a manner analogous to the well-known adverse selection issue in the insurance sector. Even where risk adjustment is used to compensate for a high proportion of high-risk individuals in the insured population in a compulsory social insurance environment, the authors argue that this will lead to significant additional distortion and therefore will not rectify the basic inefficiencies arising from the imposition of uniform premiums. These inefficiencies are outlined as static, defined with respect to risk selection effort, and dynamic, defined with respect to costreducing effort. Moving to risk-based premiums will overcome most of these inefficiencies, although they note that high-risk individuals may be excluded, through matching appropriate premiums to risk and providing incentives to consumers and insurers to counter ex ante and ex post moral hazard. Although efficiency may be achieved, the authors do note that there are equity concerns. These, it is argued, can be countered through tax-funded, hypothecated subsidies. Such subsidies would be less than $100 \%$ and related to the insurance risk, as the unsubsidised, competitive premiums would reflect individual risk.

The article is of interest not least as commonly the argument for augmenting social insurance or the privatisation of insurance is not always made explicit, and rarely explicit with regards to the concepts economists use to define efficiency, in particular Pareto optimality. ZB do make explicit reference to the

* Email: A.J.McGuire@lse.ac.uk 
Pareto defence, essentially that competitive markets are consistent with Pareto optimality, where resources (in this case through insurance contracts) would be moved to the point where it is impossible to make someone better off without making someone else worse off. Government intervention is then justified only on distributional grounds. Their proposed solution to the presence of moral hazard in insurance markets is to move toward a Pareto solution where risk-based insurance premiums would stimulate competitive pressures and a government subsidy would cover any distributional concerns. One suspects that the proposed solution is not as straightforward as outlined however.

It is not my intent to take to task all aspects of the paper, as it is stimulating and raises a number of interesting issues which would not even begin to be discussed under a more discursive treatment. However, there are specific points to note that are critical to their proposed solution, before discussing their general approach. In calculating the budgetary restructuring required to subsidise the risk-based premium in the German environment, ZB base the simulated premium on three draws from a simulated distribution of premiums disregarding any administration charge. A larger number of draws would seem warranted, or it might have been useful to use the median as one of the draws as the distribution of the loss function is bound to be skewed. More importantly the lack of account given to administrative costs is important. One argument for more choice in the insurance market is based on there being a wide heterogeneity of preferences amongst any potential insured population - a point which will be returned to below. Loading of premium may be related to both administration costs and the degree of risk aversion displayed by individuals and risk-based premiums would have to take these into account. The operation of the loading factor within the premium is therefore crucial. Both aspects, the administration costs and risk aversion, would be important in determining any additional costs incurred arising from the subsidy proposed by ZB to rectify any inequitable purchase of insurance benefit, as would any costs associated with the transfer of subsidy funds. The means tested aspect of the subsidy is a particularly important administrative cost. Such costs could be quantitatively important in assessing the relative merits of any move to risk-based premiums with in-built subsidies. But let us not go to detail, the wider picture is important.

There is the old adage concerning a Swiss tourist lost in Scotland who stops a local and asks, 'How do I get to Auchtermuchty?' After some considerable thought the local replies, 'Well, I wouldn't start from here!' The ZB piece is rather akin to this in as much as it takes a partial picture of inefficiency within the health insurance sector. The importance in this comment is that the environment in which the proposed risk-based competition-derived solutions to moral hazard are derived are far removed from any Pareto optimal environment. Moving part of that topology towards Pareto optimality, even if it were possible, would not guarantee any overall Pareto benefit. The theory of second best, tells us that, if extensive efficiency distortion exists, such as lack of 
information, the existence of compulsory purchase of insurance and/or nonlump sum subsidies, then correcting one of the many distortions will not guarantee movement to a Pareto optimum in the presence of the other distortions. This is especially true where the proposed interventions, as in the ZB case, are not of a small order of magnitude.

Given that social insurance is taken as the starting point it may be assumed that $\mathrm{ZB}$ accept that adverse selection will lead to at least some intervention. Under social insurance if premiums are related to an actuarial base, they are essentially based on low-risk individuals paying an actuarial premium plus an unavoidable lump-sum tax, while the high-risk groups pay an actuarial premium and receive a lump-sum transfer. The problems caused by the heterogeneity of risk are replaced by problems arising from heterogeneity of preferences, as standard policies do not allow for differences in preferences. If preferences are highly concentrated such that all individuals prefer full insurance there is no efficiency loss from compulsion. Charging the same premium for all risk categories, where there is small diversity of preferences, causes small loss in efficiency as arising from lack of choice. Distributional concerns are limited to the transfer between low-risk and high-risk individuals and, given the inverse linear relationship between poverty and ill-health that appears to hold widely, such re-distribution appears to be progressive with respect to income. If the compulsory social insurance is based on these quasi-actuarial premiums as related to risk, then this institutional arrangement is essentially a type of pooling (of risks) solution to adverse selection. It is the moral hazard problems as they arise from this pooling solution which $\mathrm{ZB}$ attempt to rectify through re-instatement of risk-based premiums.

Such risk-based solutions are premised on adequate, if not perfect, information for the gains from competition to be realised. It is unlikely that adequate information may be available to generate such gains. Ex ante moral hazard relies, even if there is a direct relationship between the premium and preventive effort, on the consumer recognising the complete impact of preventative effort on the various contingent health states faced. This is unlikely to be known with any great accuracy. While the links between certain consumption commodities and health are well known, cigarette smoking for example, evidence on a wide range of other preventable aspects are not. For example, precise evidence on diet, exercise and other basic 'inputs' to the production of health are currently lacking, which would make even approximate calculations relating to marginal returns on preventable activities difficult. Moreover risk-based premiums are, probably, associated with substantially higher administrative costs to cover the operating costs.

Risk-based premiums are contrasted with risk adjustment in the $\mathrm{ZB}$ argument, with the latter held to be more inefficient. Little is said of the relative costs of replacing risk adjustment with risk-based premiums. It may be noted that, even with traditional indemnity insurance, empirical evidence seems to 
suggest that levels of ex post moral hazard, as induced by the consumer, are at best moderate, with overall health care price elasticises of demand around -0.2 to -0.3 (Culter and Zeckhauser, 2000). The action in the game of moral hazard is largely on the supply side. Under systems of social insurance, control of moral hazard may be best addressed through supply-side reimbursement policies. Empirical evidence from the US, for example, suggests that utilisation review may be associated with a $10 \%$ to $15 \%$ reduction in health care costs (Glied, 2000).

As just noted the proposed ZB solutions to countering moral hazard in a social insurance system are not the only route. It may well be true that riskbased premiums hold a partial solution to the problems of, at least ex post moral hazard, even in a compulsory social insurance system where supply-side mechanisms may be readily implemented. For the ZB solution to operate adjustment of premiums to risk has to be possible and the insurance company has to operate within a budget constraint. Note that under social insurance neither condition necessarily holds. Under social insurance the contributions need not be linked to actuarial risk, and, if funding is augmented through taxation, the social insurer need not be limited to current budget balances and funding may be linked to the wider macroeconomic concerns of fiscal burden. Neither is a social insurance scheme necessarily actuarial on the benefits side. A private insurance contract, written with knowledge of the full contingencies faced by the consumer, specifies the link between these contingencies and the resulting benefits. This private contract, or the quasi-private risk-based premium proposed by $\mathrm{ZB}$, is not open to variation. A social insurance contract is potentially more flexible; although there is always a risk of reducing benefits under such a scheme. Such flexibility allows coverage to respond to, for example, the use of new pharmaceutical products or new surgical techniques, and the related changes in health care costs, in a less constrained manner than the tying of premiums to actuarial risk may do. In other words, there is no compulsion to relate social insurance contributions to average actuarial risk and there may be dynamic efficiency advantages in not doing so.

As ever, all is relative. The case for any change within a particular health care insurance system cannot be made through appeal to general principles. If there is a weakness in the argument suggested by $\mathrm{ZB}$, it is that there is an inferred appeal to the Paretian principle and this is hard to justify with respect to insurance markets generally, as well as with respect to their own specific issue of introducing risk-based premium within a social insurance setting. Necessarily we are dealing with a second-best world. The $\mathrm{ZB}$ article does raise a very interesting question however, concerning the relative efficiency of risk adjustment and risk sharing, where the latter need not be confined to demand-side cost sharing. Very little theoretical or empirical analysis has been undertaken on this question as noted by Van de Ven and Ellis (2000). A clear setting out of the basic mechanisms through which risk adjustment and risk setting operate 
within a managed care setting, and their interaction with supply-side risksharing mechanisms would be a very useful, if ambitious, project. The work by Newhouse (2002) highlights how extensive and broad such a coverage would have to be. The trade-offs made between addressing the heterogeneity of risk in an insured population, the heterogeneity of preferences with respect to coverage and the supply-side responses to any proposed solutions to these trade-offs is a central issue in the design of funding mechanisms in health care generally. $\mathrm{ZB}$ add to this literature by covering some of the technical issues in a useful manner. Much remains to be done.

\section{References}

Culter, D. and R. Zeckhauser (2000), 'Insurance markets, managed care and contracting', in A. Culyer and J. Newhouse (eds), The Handbook of Health Economics, Amsterdam: North-Holland.

Glied, S. (2000), 'Managed care', in A. Culyer and J. Newhouse (eds), The Handbook of Health Economics, Amsterdam: North-Holland.

Newhouse, J. (2002), Pricing the Priceless: A Health Care Conundrum, Cambridge, MA: MIT Press.

Van de Ven, W. and R. Ellis (2000), 'Risk adjustment in competitive health plan markets', in A. Culyer and J. Newhouse (eds), The Handbook of Health Economics, Amsterdam: North-Holland. 